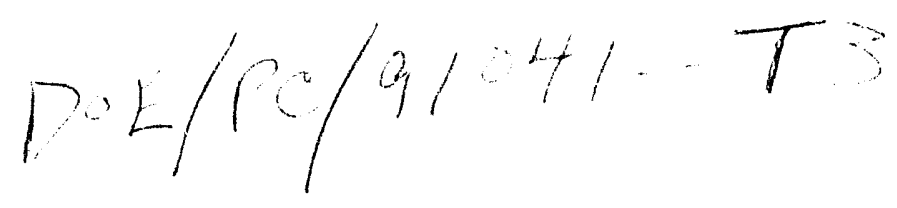

\title{
PRECONVERSION PROCESSING OF BITUMINOUS COALS \\ - NEW DIRECTIONS TO IMPROVED DIRECT CATALYTIC COAL LIQUEFACTION -
}

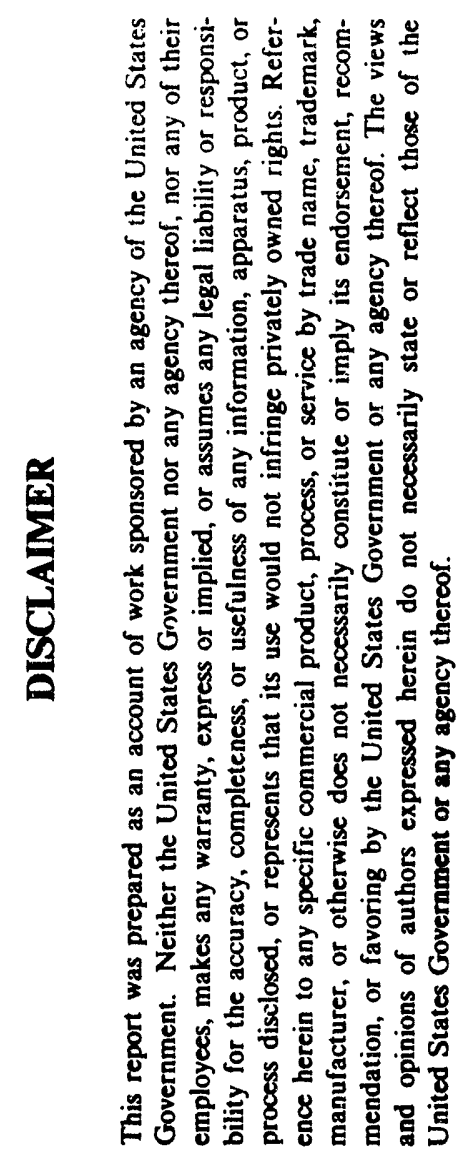

DOE Contract No. DE-AC22-91PC91041

DOE/PC/91041-T3

\author{
Prepared for \\ U.S. Department of Energy \\ Pittsburgh Energy Technology Center \\ P.O. Box 10940 \\ Pittsburgh, PA 15236
}

Quarterly Report

$(1 / 1 / 92-3 / 31 / 92)$

(BCRNL Report L-1658)

July 1992

DE93 000732

BCR National Laboratory
500 William Pitt Way
Pittsburgh, PA 15238

An Affiliate of the University of Pittsburgh

"US/DOE Patent: Clearance is not required prior to the publication of this document"

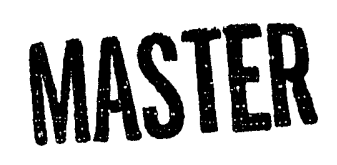




\section{TABLE OF CONTENTS}

\section{Page}

A. Effect of High-Temperature Soaking............ 1

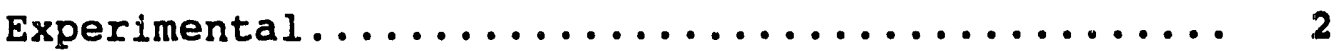

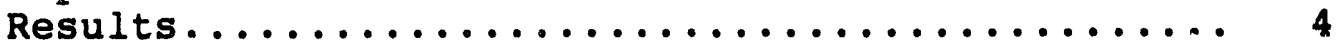

References........................... 4

B. Strong Interactions Between Selective Compounds

and coal............................. 6

Experimental.......................... 7

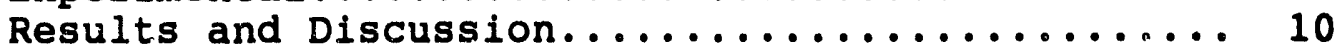

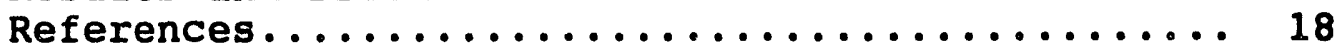

Figure Legends........................... 20 


\section{LIST OF FIGURES}

Fiqure

Page

1 Effect of Nature of Coal Liquid on Extractability (Pyridine, Tetrahydrofuran, and

Toluene) During High-Temperature Soaking....

\section{LIST OF TABLES}

Table

Page

1

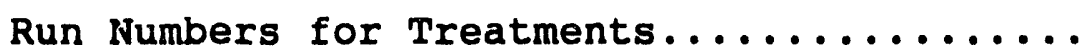

2

Approximate Recoveries (wt 8 ) of Compounds

After Treatments in Cyclohexane..........

Recovery and Normalized Yields of Each

Fraction by Neutral Alumina Fractionation...

4 Elemental Analyses of Original and Adsorbed Coal Liquids. 


\section{INTRODUCTION}

A study of the high-temperature soaking started in this quarter, following the installation of reactors in the previous quarter. Two high-volatile bituminous coals and three coal liquids, which were identified in the previous report, were used. The selective interaction between coal and a coal liquid during the high-temperature soaking was also investigated, using the Illinois No. $6 \mathrm{coal}$ and the coal liquid derived from the Illinois No. 6 . coal.

\section{A. Effect of High-Temperature Soaking}

A cross-linked, three-dimensional macromolecular model has been widely accepted for the structure of coal, but there is no direct evidence to prove this model. The conventional coal structure model has been recently re-examined by this investigator $^{2}$ because of the importance of relatively strong intra- and intermolecular interactions in bituminous coals. It was reasonable to deduce that significant portions were physically associated after a study of multistep extractions, associative equilibria, the irreversibility and the dependence of coal concentration on solvent swelling, and consideration of the monophase concept. Physical dissociation which may be significant above $300^{\circ} \mathrm{C}$ should be utilized for the treatment before liquefaction. The high-temperature soaking in a recycle oil was proposed to dissociate coal complexes in this project.

Coal-derived liquids are expected to be very good solvent systems at high temperature because materials derived from the same coal are supposed to contain electron donors and acceptors of low molecular weight. These molecules, with donor and acceptor capa- 
molecular weight. These molecules, with donor and acceptor capabilities, would break charge-transfer complexes in high-volatile bituminous coal by substituting coal-coal complexes with these molecules, especially at high temperatures ${ }^{1}$. To investigate this high-temperature soaking, Illinois No. 6 and Pittsburgh No. 8 coals were soaked in three different coal liquids at $350^{\circ} \mathrm{C}$. Effect of the high-temperature soaking was examined by solvent extraction with three solvents: toluene, tetrahydrofuran (THF), and pyridine. The systematic study of the high-temperature soaking using three different solvents has not been reported.

\section{EXPERIMENTAL}

Illinois No. 6 (DECS-2) and Pittsburgh No. 8 (DECS-12) coal samples were obtained from DOE Coal Data and Sample Bank at Pennsylvania State University. The elemental analysis of Illinois No. 6 coal are as follows (wt8, dry basis): ash:16.2, C:65.5, H:4.6, N:1.1, S:4.5, and that of Pittsburgh No. 8 coal are (wtz, dry basis): ash:10.3, C:74.8, H:5.1, N:1.2, S:1.1. The coal samples for high-temperature soaking studies were used as-recelved. HPLC-grade solvents used for extraction were purchased from Fisher Scientific Company (Pittsburgh, PA) and were used without further purification.

Before the start of the experiment, the microreactor was thoroughly cleaned and flushed with acetone and dried in an oven maintained at $104^{\circ} \mathrm{C}$. During a typical run, the reactor was charged with predetermined amounts of coal (as-received) and solvent. After charging the contents, the multiport valve was attached to 
the reactor and tightly sealed. This was followed by purging the reactor three times with nitrogen to provide an inert environment. The reactor was then repressurized with the ambient gas, and the reactor assembly was fixed to the horizontal shaker unit. After starting the shaker unit, the reactor was immersed in the sand bath, which was maintained at the predetermined reaction temperature. At the beginning, as the reactor was being immersed into the sand bath, the temperature of the sand bath dropped by 10 degrees, however, the sand bath reached the set point temperature within four minutes or less. Due to the very high rates of heat transfer in fluidized sand bath, the reactor and its contents attained the sand bath temperature within three minutes.

After conducting the experiment for the desired duration of the reaction time, the lift table was lowered rapidly and the reactor was cooled to room temperature by blowing air frum a fan. After cooling the reactor, the gaseous products were vented in the hood, and the multiport valve was disconnected. The reactor contents were quantitatively removed from the reactor, and repeatedly washed with pyridine until the washing solution from the reactor became colorless. This was followed by filtering the reactor contents through an extraction thimble, followed by soxhlet extraction with pyridine until the solution draining from the thimble became colorless. The extraction, however, was carried out for a minimum period of 24 hours. The extraction thimble containing residue (pyridine insolubles) was further soxhlet washed with methanol for a period of six hours and then dried overnight in a vacuum oven at 
$95^{\circ} \mathrm{C}$, or for a period of eight hours. The pyridine from the extract containing pyridine solubles was stripped off by evaporation under vacuum in the rotavapor, and an excess of THF was added to precipitate THF insolubles, and THF extraction in the soxhlet apparatus was carried out as above until the solution draining from the thimble became colorless, or for a minimum period of six hours. This was followed by further precipitating THF solubles by adding an excess of toluene and carrying out toluene extraction. The amounts of pyridine solubles, THF solubles, and toluene solubles were determined from the weight of the respective insolubles.

\section{RESULTS}

The conversion by the high-temperature soaking was examined by extractability with three solvents: toluene, THF, and pyridine. These results are shown in Figure 1. Pyridine extractabilities were more than $70 \mathrm{wt}$ for all cases. Coal tar distillate gave the highest pyridine extractability for both coals, but the lowest toluene extractability. A higher pyridine extractability (5-10 wt8) was obtained for the Illinois No. 6 coal than for the Pittsburgh No. $8 \mathrm{coal}$. Other systematic experiments on the effect of temperature and residence time are underway. The effect of the high-temperature soaking on coal dissolution and its mechanism will be investigated in the next quarterly report.

\section{REFERENCES}

1. Nishioka, M., Fuel in press. 


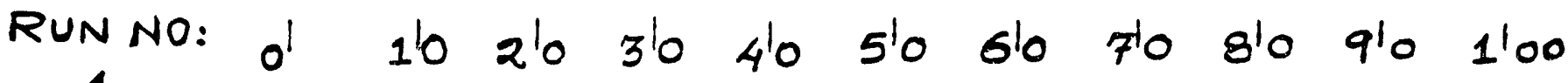
1

2

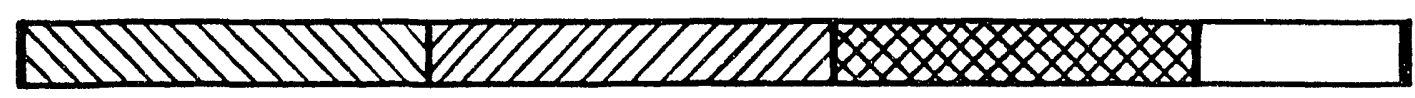

3

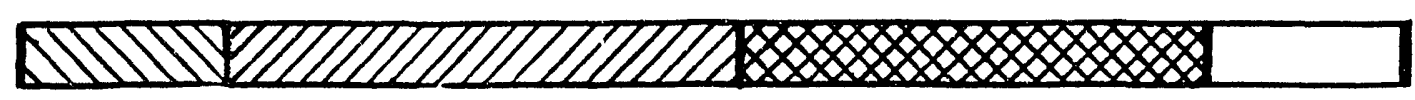

TOLUENE WOLATHF THELES PYRIDNE
SOLUBLES RESIDUE

4

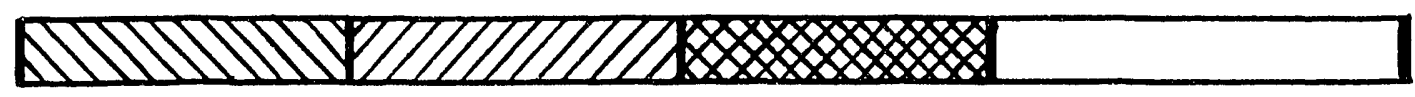

5

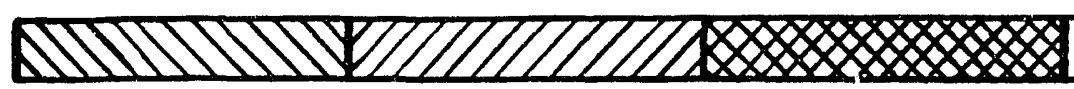

6

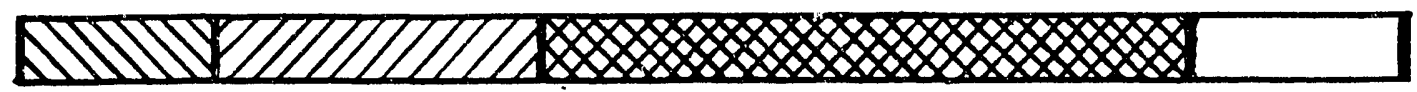

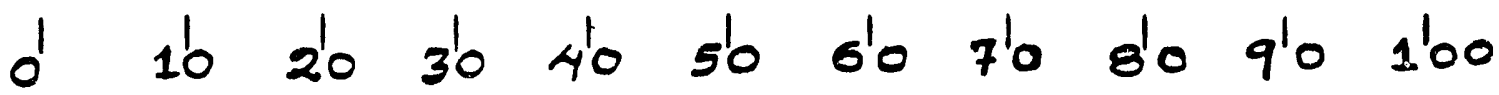

Run No.

1. Illinois \#6 Coal + Illinois Coal Liquid @ $350^{\circ} \mathrm{C} / 50$ Psig $\mathrm{N}_{2} / 2 \mathrm{Hr}$

2. Illinois \#6 Coal + Pittsburgh Coal Liquid @ $350^{\circ} \mathrm{C} / 50 \mathrm{Psig} \mathrm{N}_{2} / 2 \mathrm{Hr}$

3. Illinois \#6 Coal + Coal Tar Distillate @ $350^{\circ} \mathrm{C} / 50 \mathrm{Psig} \mathrm{N}_{2} / 2 \mathrm{Hr}$

4. Pittsburgh \#8 Coal + Illinois Coal Liquid @ $350^{\circ} \mathrm{C} / 50$ Psig $\mathrm{N}_{2} / 2 \mathrm{Hr}$

5. Pittsburgh \#8 Coal + Pittsburgh Coal Liquid @ $350^{\circ} \mathrm{C} / 50$ Psig $\mathrm{N}_{2} / 2 \mathrm{Hr}$

6. Pittsburgh \#8 Coal + Coal Tar Distillate @ $350^{\circ} \mathrm{C} / 50$ Psig $\mathrm{N}_{2} / 2 \mathrm{Hr}$

Figure 1. Effect of Nature of Coal Liquid on Extractability (Pyridine, Tetrahydrofuran, and Toluene) During High-iemperature Soaking 


\section{B. STRONG INTERACTIONS BETWEEN SELECTIVE COMPOUNDS AND COAL}

It is known that pyridine is retained in both extract and residue after a soxhlet extraction procedure ${ }^{1-5}$. Pyridine is not completely removed from these materials even after drying under high vacuum at around $100^{\circ} \mathrm{C}$. The amount of retained pyridine reaches 1-10 wtz. As retained pyridine is easily exchangeable with free pyridine', this is a physical incorporation in coal.

Maleic anhydride is incorporated in high-volatile bituminous coal by heating at $100-200^{\circ} \mathrm{C}$ in solvents such as benzene and chlorobenzene $e^{6 \cdot 8}$. A portion of incorporated maleic anhydride is the adduct of the Diels-Alder reaction, but a significant anount of unreacted maleic anhydride is physically retained ${ }^{9}$. Although maleic anhydride is easily dissolved in water and methanol, the recovery of the adsorbed maleic anhydride was difficult with water and methanol.

It is known that hydrogen bonds are major interactions in lower ranks of coal'10.12. Compounds containing functional groups such as $-\mathrm{OH}$ and $-\mathrm{NH}$ - interact with coal by hydrogen bonds. As it is estimated that most hydrogen bonds can be broken with pyridine ${ }^{13,14}$, such compounds would be readily recovered with pyridine. However, if interactions between coal and such compounds are relatively strong, these compounds may not be completely recovered with pyridine. The charge-transfer interaction is one of the important relatively strong interactions in high-volatile bituminous $\operatorname{coal}^{15}$. Some portions of charge-transfer complexes in the coal cannot be solvated with pyridine ${ }^{15}$, although pyridine is a good 
electron donor solvent. Charge-transfer complexes i.n original coal are readily broken at higher temperature, and more stable chargetransfer complexes are formed. Therefore, the strength and abundance of selective interactions or complexes in coal may change at higher temperature.

Interactions between selected molecules and coal have not been fully studied. Coal is mixed with a recycle oil in coal liquefaction. Compounds in a recycle oil may be selectively adsorbed on coal, and have a considerable effect on preconversion of coal and liquefaction.

In this section, selective interactions in the Illinois No. 6 coal were studied by using various types of standard compounds and the coal liquid derived from the Illinois No. 6 coal. The mixture of standards/coal and the coal liquid/coal were soaked at three different temperatures, and their recoveries were examined by Soxhlet extraction. Selective interactions in the coal were investigated based on these recoveries.

\section{EXPERMENTAL}

The $10 \mathrm{~g}$ coal was Soxhlet-extracted with pyridine for 72 hours, Soxhlet-rinsed with methanol for 24 hours, and dried under vacuum at $95^{\circ} \mathrm{C}$ overnight. This residue (PI) was also used in the study. A coal liquid derived from Illinois No. 6 coal obtained from the Wilsonville pilot plant ${ }^{16}$ was used. All the reagents and solvents were obained from Aldrich Chemical Co. (Milwaukee, WI) and Fisher Scientific (Pittsburgh, PA), and HPLC-grade solvents were 
used. Tetrahydrofuran (THF) was distilled before use; the other reagents were used without purification.

Coal samples $(5 \mathrm{~g}$ ) were charged into a $250 \mathrm{ml}$ autoclave (Model 4576, Parr Instrument Co., Moline, IL). The $10 \mathrm{ml}$ coal liquid and $50 \mathrm{ml}$ cyclohexane were added. The autoclave was evacuated and purged with nitrogen five times, and then heated at approximately $5^{\circ} \mathrm{C} \mathrm{min}^{-1}$ to 200 and $350^{\circ} \mathrm{C}$ under nitrogen (initial pressure: 0.35 MPa). The mixtures were heated at 200 or $350^{\circ} \mathrm{C}$ for two hours, agitating with the autoclave stirrer $\left(500 \mathrm{rev} \mathrm{min}^{-1}\right)$. For the treatment at room temperature, the mixtures were agitated under nitrogen in a $500 \mathrm{ml}$ flask by magnetic stirring. The same procedure was carried out for the treatment of PI and a standard compound solution in methylene chloride $\left(0.05 \mathrm{~g} \mathrm{ml}^{-1}\right)$ were charged. After these treatments, the mixtures were filtered and soxhletextracted for 24 hours. The outline of these procedures is summarized in Table 1.

Original and recovered coal liquids after the treatment were fractionated into chemical classes by column adsorption chromatography on neutral alumina ${ }^{17}$. These fractions and standard compounds were analyzed by using a gas chromatograph (GC), HewlettPackard Model 5840A equipped with a flame ionization detector. Sample injection was made in the split mode (1:20 ratio), and the hydrogen carrier gas was set at a linear velocity of $80 \mathrm{~cm} \mathrm{~s}^{-1}$. The fused silica capillarv column ( $15 \mathrm{~m} \times 0.25 \mathrm{~mm}$ i.d.) coated with SE54 (film thickness of $0.25 \mu \mathrm{m}$ ) was obtained from sUPELCO, Inc. 
TABLE' 1. RUN NUMHBERS FOR TREATIAENTS

Run No. Treatment

Residue + a standard mixture: soaked in cyclohexane at $25^{\circ} \mathrm{C}$ for $2 \mathrm{~h}$, followed by Soxhlet extraction with cyclohexane, THF and pyridine for $24 h$, respectively

2 Residue + a standard mixture: soaked in cyclohexane at $200^{\circ} \mathrm{C}$ for $2 \mathrm{~h}$, followed by Soxhlet extraction with cyclohexane, THF and pyridine for $24 h$, respectively

3 Residue + a standard mixture: soaked in cyclohexane at $350^{\circ} \mathrm{C}$ for $2 \mathrm{~h}$, followed by Soxhlet extraction with cyclohexane, THF and pyridine for $24 \mathrm{~h}$, respectively

4 Residue + a coal liquid: soaked in cylohexane at $25^{\circ} \mathrm{C}$ for $2 \mathrm{~h}$, followed by Soxhlet extraction with cyclohexane and THF for $24 \mathrm{~h}$, respectively

5 Residue + a coal liquid: soaked in cylohexane at $200^{\circ} \mathrm{C}$ for $2 \mathrm{~h}$, followed by Soxhlet extraction with cyclohexane and THF for $24 \mathrm{~h}$, respectively Residue + a coal liquid: soaked in cylohexane at $350^{\circ} \mathrm{C}$ for $2 \mathrm{~h}$, followed by Soxhlet extraction with cyclohexane and THF for $24 \mathrm{~h}$, respectively

7 Coal + a coal liquid: soaked in cyclohexane at $25^{\circ} \mathrm{C}$ for $2 \mathrm{~h}$, followed by filtration and evaporation of the solvent

8 Coal + a coal liquid: soaked in cyclohexane at $200^{\circ} \mathrm{C}$ for $2 \mathrm{~h}$, followed by filtration and evaporation of the solvent

9 Coal + a coal liquid: soaked in cyclohexaine at $350^{\circ} \mathrm{C}$ for $2 \mathrm{~h}$, followed by filtration and evaporation of the solvent 
(Bellefonte, PA). Elemental analyses of coal liquids were conducted by Geochemical Testing (Somerset, PA) .

\section{RESULTS AND DISCUSSTON}

Four types of standard compounds were mixed with PI in cyclohexane at 25,200 , and $350^{\circ} \mathrm{C}$ for two hours. These compounds are (1) neutral compounds: eicosane and phenanthrene, (2) an electron acceptor compound: anthraquinone, (3) electron donor and basic compounds: carbazole and acridine, and (4) hydroxyl and weak acidic compounds: tetrahydronaphthol, naphthol, and phenylphenol. Approximate recoveries with cyclohexane, THF, and pyridine were analyzed by GC. These results are shown in Table 2 .

Nearly 100 percent of neutral compounds, eicosane, and phenanthrene were recovered with cyclohexane after all treatments. Recovery of phenanthrene was more than 100 percent afiter the treatment at 200 and $350^{\circ} \mathrm{C}$, presumably due to production from $\mathrm{PI}^{18}$. Although nearly 100 percent of anthraquinone was recovered with cyclohexane after the treatment at $25^{\circ} \mathrm{C}$, only 10 percent of the compound was recovered with cyclohexane after the treatment at $200^{\circ} \mathrm{C}$. All remaining adsorbed anthraquinone on PI was recovered with THF. While no anthraquinone was recovered with cyclohexane after the treatment at $350^{\circ} \mathrm{C}, 60$ percent of anthraquinone was recovered with THF. It is not known whether the remaining 40 percent of anthraquinone was very strongly adsorbed or reacted with PI, but the resulting no recovery with cyclohexane shows the strong interaction between the coal (PI) and anthraquinone. 
TABLE 2. APPROXIMATE RECOVERIES ( $w$ t\%) OF COMPOUNDS AFTER TREATMENTS IN CYCLOHEXANE

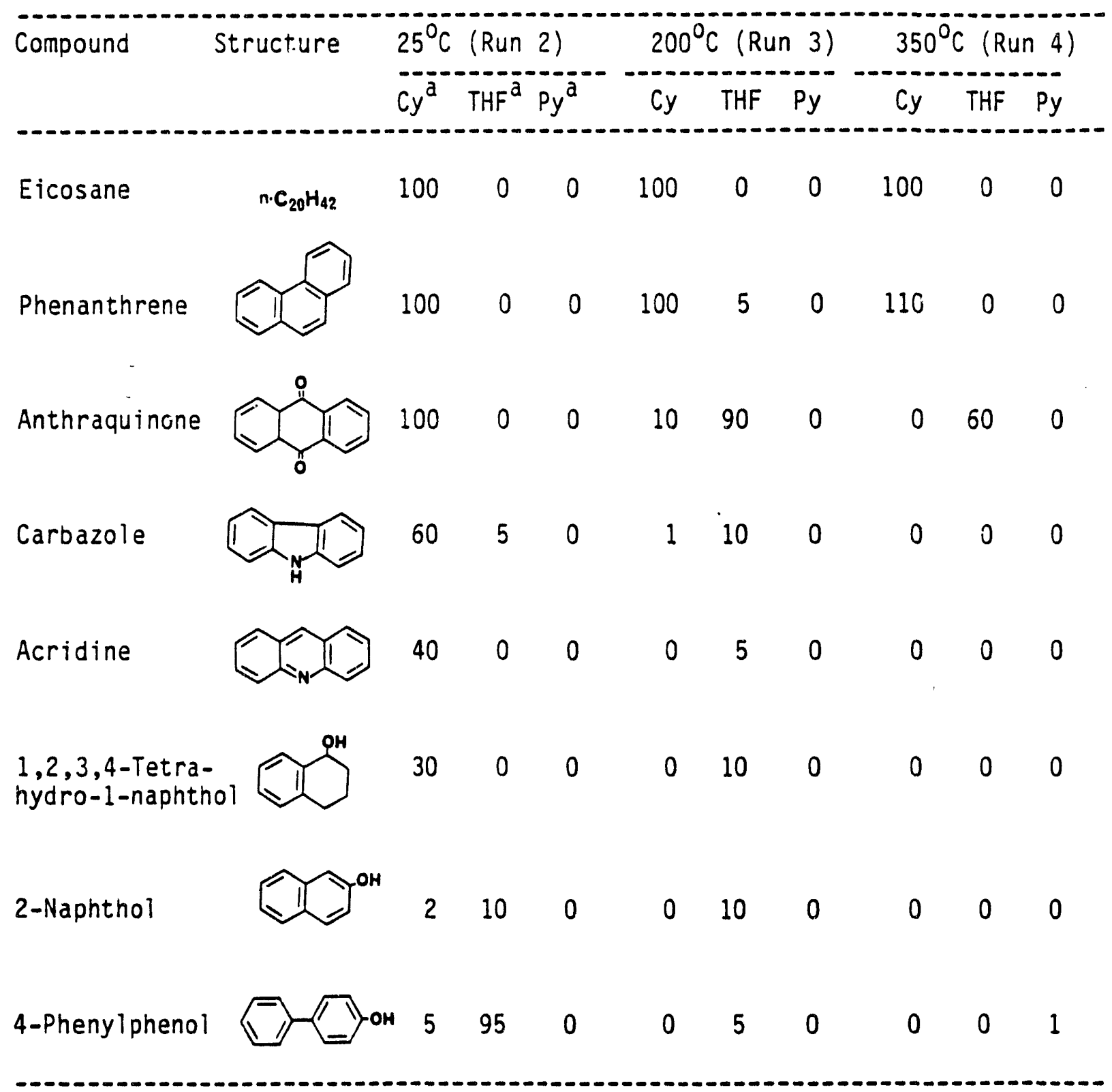

${ }^{a}$ Cy, Cyclohexane; THF, Tetrahydrofuran; Py, Pyridine

$b_{\text {Recovery }}$ less than $1 \%$ was regarded as 0 
Maleic anhydride is a diketones with the similar structure to anthraquinone. The Diels-Alder reaction was conducted by soaking coal with maleic anhydride in chlorobenzene at $115^{\circ} \mathrm{C}$ for seven days $^{9}$. A significant amount of unreacted maleic anhydride was recovered by extraction with THF, even after thorough washing reacted coals with water or methanol ${ }^{9}$. The strong adsorption of both anthraquinone and maleic anhydride by these soakings is consistent.

The strong adsorption of basic and weakly acidic compounds on the coal (PI) is very notable, as shown in Table 2. Remaining phenylphenol, after extraction with cyclohexane after the treatment at $25^{\circ} \mathrm{C}$, was recovered with THF, but other remaining compounds were not recovered with THF and pyridine. Recoveries of the weakly acidic compounds were smaller than those of the basic compounds. Carbazole, acridine, and naphthol are presumably not so labile at $350^{\circ} \mathrm{C}$ because these are found to be major constituents in a coal liquid and a coal tar ${ }^{19}$. These results imply that these compounds are strongly adsorbed on the coal, and that the interaction between coal and the weak acidic compounds is stronger than that between the coal and the basic compounds. It can be interpreted that the interaction or adsorption became stronger with an increase in temperature of the treatment. It should be noticed that only less than 10 percent of these compounds were recovered with good solvents of THF and pyridine after the treatment at more than $200^{\circ} \mathrm{C}$. 
Further, the adsorption was investigated by using the coal liquid. Runs 4-6 (see Table 1) were conducted exactly following the above procedure. Recovery with THF, after extraction with cyclohexane, was regarded as adsorbed coal liquid fractions. The amounts of adsorbed coal liquids from the $10 \mathrm{~g}$ sample were 0.03 , 1.5, and $1.9 \mathrm{~g}$ at 25,200 , and $350^{\circ} \mathrm{C}$, respectively. It is seen that the adsorbed coal liquid increased with an increase in temperature of the treatment. This result is consistent with the trend observed for standard compounds.

These original and adsorbed coal liquids were fractionated into chemical classes, and the yield of each fraction was investigated. The A-1 to A-4 fractions are composed of neutral aliphatics, neutral aromatics, basic aromatics, and weakly acidic aromatics, respectively ${ }^{17}$. Total recovery by this adsorption chromatography was 85-95 percent, and their normalized yields are shown in Table 3. It is seen that adsorbed coal liquids are composed of large amounts of $A-3$ and $A-4$ fractions, and the ratio of A-3 to A-4 decreased for the higher temperature treatment.

Change in the chemical composition of the coal liquid during the treatment was checked. The original coal and the coal liquid were treated under the same condition. The yields by the adsorption chromatography for these treated coal liquids are also listed in Table 2. Although the A-1 fraction decreased and the A-2 fraction increased with an increase in temperature of the treatment, A-3 and A-4 fractions did not change to explain the higher yields of $A-3$ and A-4 fractions for the adsorbed coal liquids shown 
TABLE 3. RECOVERY AND NORMALIZED YIELDS OF EACH FRACTION BY NEUTRAL ALUMINA FRACTIONATION

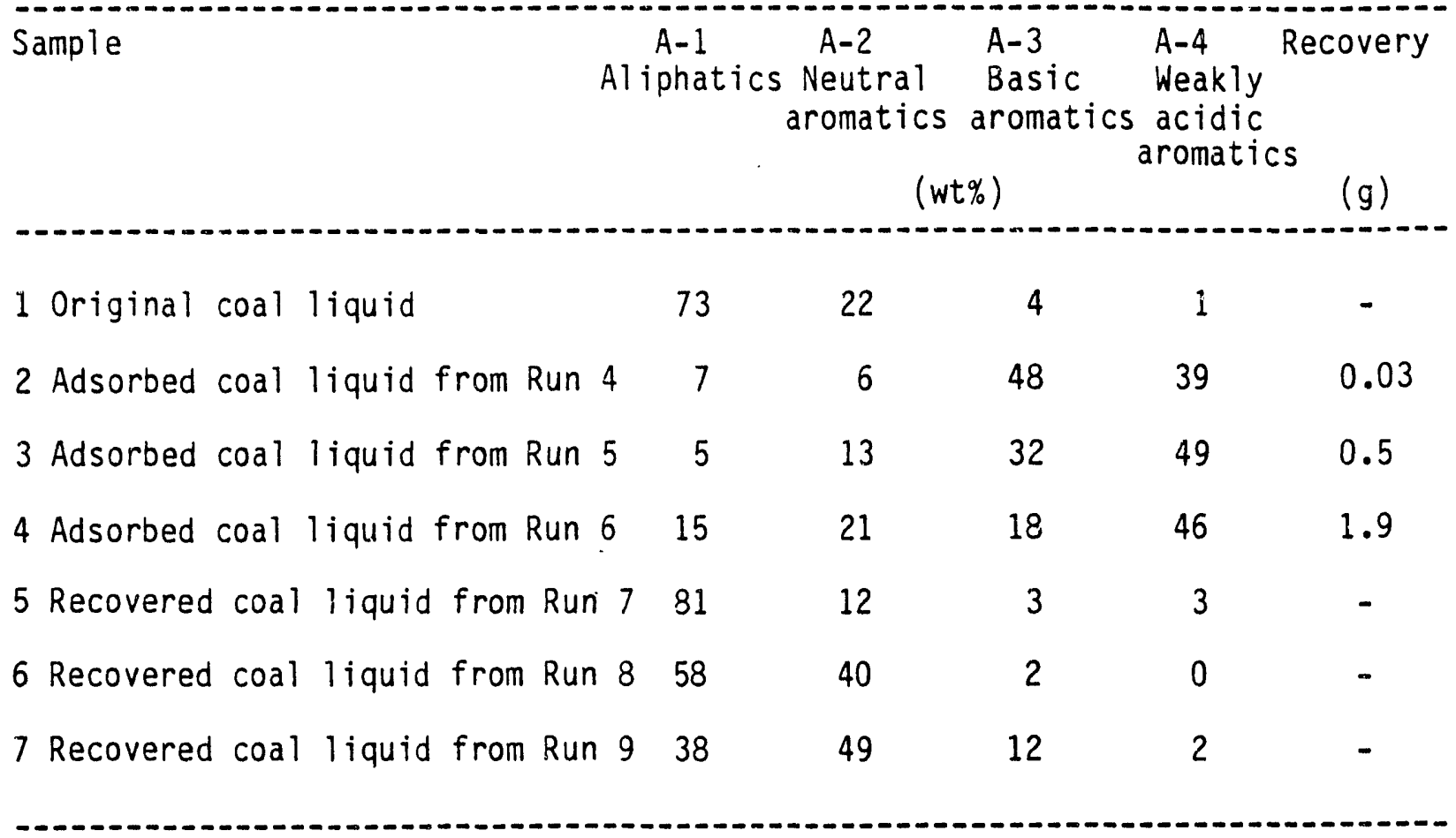


above. Therefore, the result supports that basic and weak acidic aromatics in the coal liquid were strongly adsorbed on coal, and that weak acidic aromatics are adsorbed more strongly than basic aromatics. These are consistent with the results obtained by using various standard compounds.

The elemental analysis of the adsorbed coal liquid at $350^{\circ} \mathrm{C}$ (Sample 4 in Table 3) was compared with that of the original coal liquid. Much higher contents of heteroatoms in the sample are noticed as shown in Table 4. Although this fraction may contain adsorbed THF solubles produced from PI at $350^{\circ} \mathrm{C}$ to some extent, the result implies the strong interaction between selected molecules such as basic and weak acidic componnds and coal. It is also seen that this adsorbed fraction is more aromatic from the comparison of the atomic $\mathrm{H} / \mathrm{C}$ ratio between the original and the adsorbed coal 1 iquids.

Each fraction shown in Table 3 was analyzed by GC. The significant differences in GC chromatograms for all the neutral aliphatic and aromatic fractions ( $A-1$ and $A-2)$ were not seen among the samples. However, compounds elutable under the GC condition in the A-3 and A-4 fractions from adsorbed coal liquids significantly decreased with an increase in the temperature of the treatment. Figure 1 compares the chromatograms of the A-3 fractions from Samples 1, 4, and 7 (see Table 3). The 50 ng A-3 fraction from Sample 1 and $500 \mathrm{ng}$ A-3 fractions from Samples 4 and 7 were injected, respectively. The A-3 fraction of sample 4 did not contain a significant amount of the basic aromatics with low- 
TABLE 4. ELEMENTAL ANALYSES OF ORIGINAL AND ADSORBED COAL LIQUIDS

$\begin{array}{llllll}\text { Sample } & & \text { Element }(\text { wt\%) } & & \text { Atomic } \mathrm{H} / \mathrm{C} \\ \text { ratio }\end{array}$


molecular mass, as seen in chromatogram B. The basic aromatics with low-molecular mass are also less abundant in the A-3 fraction from Sample 7, as seen in chromatogram C. The A-4 fraction of Sample 4 also did not contain a significant amount of the weak acidic aromatics with low-molecular mass. Detailed identification of these compounds in the $A-3$ and $A-4$ fractions was difficult, but results coincide with the fact that the basic and weak acidic aromatics were not recovered with THF after the treatment at 200 and $350^{\circ} \mathrm{C}$. It is interpreted that basicity and acidity of major constituents in these $A-3$ and $A-4$ fractions from adsorbed coal liquids would not be so strong as acridine, carbazole, and naphthol, and may be aromatic and high-molecular-mass material.

Above results using standard compounds and the coal liquid showed that interactions between some sorts of compounds and coal are quite strong. These compounds include basic and weak acidic aromatics. The strong adsorption was found even at room temperature, and these compounds were not easily recovered with good solvents such as THF and pyridine. The adsorption is promoted by the heat treatment. The higher the temperature of the treatment, the stronger will be the adsorption. This is presumably due to the change in an equilibrium between coal and molecules adsorbed at high temperature. The complete recovery of the compounds strongly adsorbed onto coal at higher temperature was very difficult, even when using one of the best solvents, pyridine.

The solvent-induced association is formed by soaking of highvolatile bituminous coal 20,21 . The degree of association is highly 
dependent upon solvent and temperature. It was interpreted that coal molecules change their conformations by soaking and tend to attain more stable and associated states. This is attributed to the change in an equilibrium between associated and dissociated coal molecules. The complete solvation of complexes formed was very difficult with soxhlet pyridine extraction. This resulted in a decrease in pyridine extractability of the coal. The strong adsoxption of selective molecules on coal found in this study and the solvent-induced association are presumably the similar physical phenomenon. The difference would be their molecular sizes. The adsorption would be dependent on ranks of coal, solvent, and temperature, because of the high dependence of the solvent-induced association on these factors.

\section{REFERENCES}

1. Collins, C. J., Hagaman, E. W., Jones, R. M., and Rasen, V. F., Fuel 1981, 60, 359.

2. Squires, T. G., Venier, C. G., Hunt, J. D., Shei, J. C., and Smith, B. F., Fuel 1982, 61, 1170 .

3. Narain, N. K., Utz, B. R., Appell, H. R., and Blaustein, B. D., Fuel 1983, 62, 1417 .

4. Chambers, R. R., Jr., and McKamey, D., Fuel 1984, 63, 868 .

5. Cooke, N. E. and Gaikwad, R. P., Fuel 1984, 63, 1468 .

6. Duty, R. C. and Lin, H. F., Fuel $1980,59,546$.

7. Larsen, J. W. and Lee, D., Fuel 1983, 62, 1351.

8. Quiga, E. M. Y. and Larsen, J. W., Energy \& Fuels 1987 , 1,300 .

9. Nishioka, M., Energy \& Fuels 1991, 5, 523. 
10. Painter, P. C., Graf, J., and Coleman, M. M., Energy \& Fuels 1990, 4, 379.

11. Painter, P. C., Park, Y., Sobkowiak, M., et al., Energy \& Fuels $1990,4,384$.

12. Painter, P. C., Graf, J., and Coleman, M. M., Energy \& Fuels $1990,4,393$.

13. Larsen, J. W. and Baskar, A. J., Energy \& Fuels 1987,1 , 230 .

14. Painter, P. C., Sobkowiak, M., and Youtcheff, J., Fuel $1987,66,973$.

15. Nishioka, M., Gebhard, L. A., and Silbernagel, B. G., Fuel 1991, 70, 341 .

16. Gollakota, S. V., Lee, J. M., and Davies, 0., Fuel. Proc. Tech. $1989,22,205$.

17. Later, D. W., Lee, M. L., Bartle, K. D., Kong, R. C., and Vassilaros, D. L., Anal. Chem. 1981, 53, 1612 .

18. Nishioka, M. and Larsen, J. W., Energy \& Fuels 1988, 2, 351 .

19. Nishioka, M. and Lee, M. L. in 'Polynuclear Aromatic Compounds' (Ed. L. B. Ebert), American Chemical Society, Washington, DC 1989 , Ch. 14 .

20. Nishioka, M. and Larsen, J. W., Energy \& Fuels 1990,4 , 100 .

21. Nishioka, M. and Larsen, J. W., Prepr. Am. Chem. Soc. Div. Fuel Chem. 1990, 35(2), 319. 


\section{FIGURE LEGENDS}

Figure 1 Gas chromatograms of basic aromatic fractions (A-3) of (A) Sample 1, (B) Sample 4 and (C) Sample 7 (see Table 3). Conditions are as follows: $40-120^{\circ} \mathrm{C}$ at $10^{\circ} \mathrm{C} \mathrm{min}^{-1}$ and $120-250^{\circ} \mathrm{C}$ at $4^{\circ} \mathrm{C} \mathrm{min}^{-1}$ after an initial 2-min isothermal period 


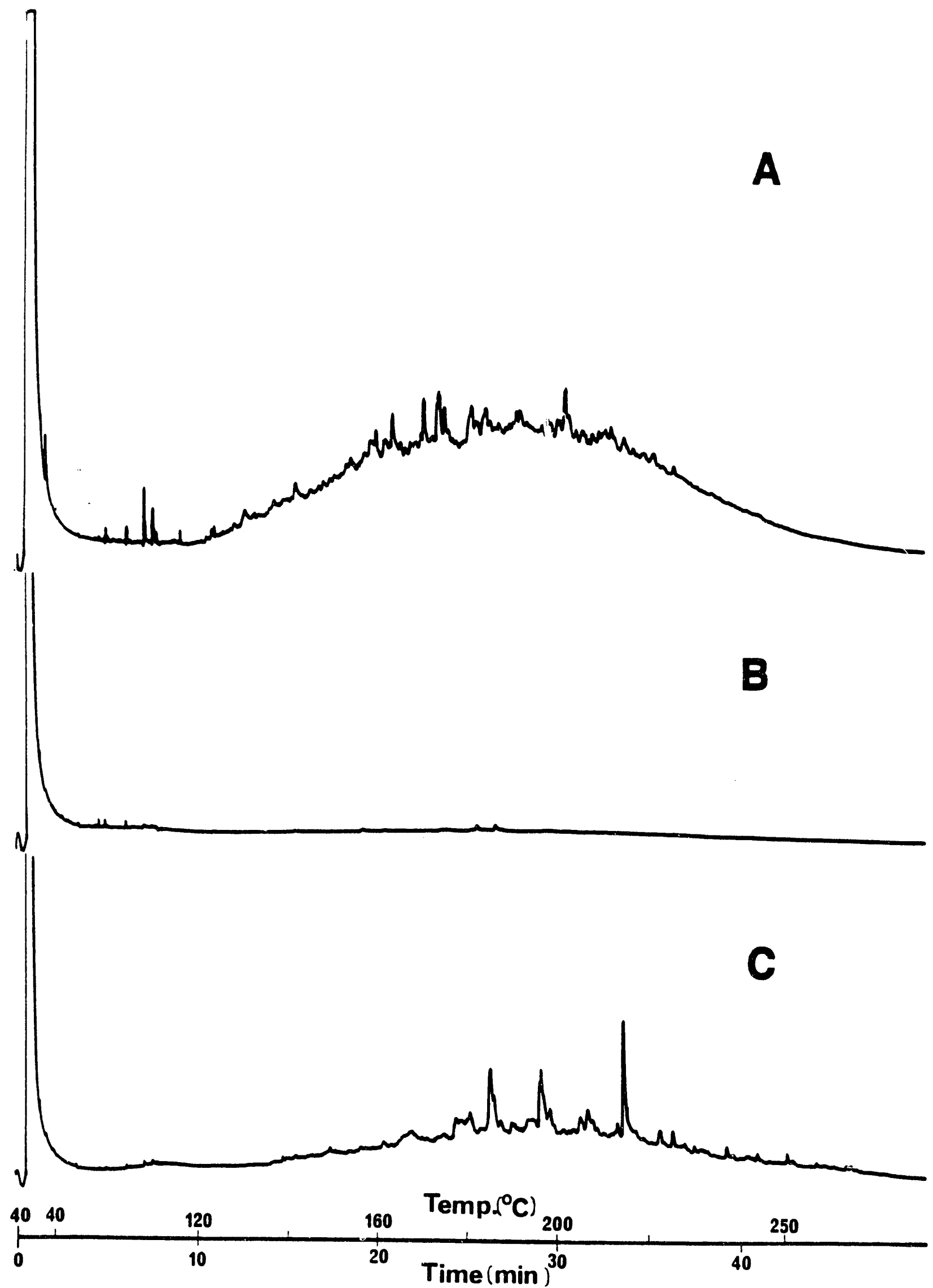



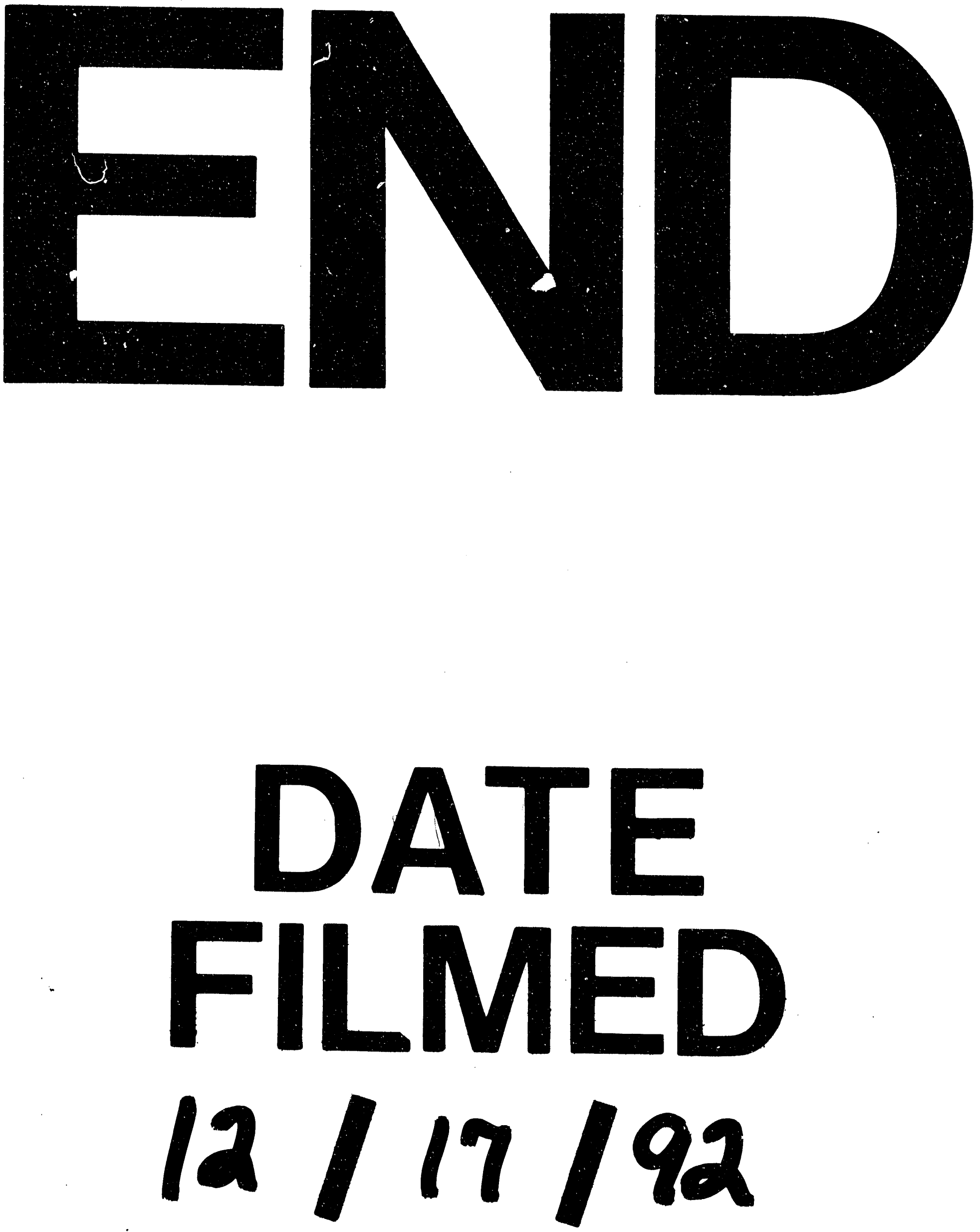
